\title{
Stable inhibition of interleukin 1 receptor type II in Ishikawa cells augments secretion of matrix metalloproteinases: possible role in endometriosis pathophysiology
}

\author{
S Guay ${ }^{1,2}$ and A Akoum ${ }^{1,2}$ \\ ${ }^{1}$ Unité d'Endocrinologie de la Reproduction, Centre de Recherche, Hôpital Saint-François d'Assise, Centre Hospitalier \\ Universitaire de Québec, 10 rue de l'Espinay, Local D0-711, Québec, Canada, G1L 3L5 and ${ }^{2}$ Département \\ d'Obstétrique et Gynécologie, Faculté de Médecine, Université Laval, Québec, Canada, GIV 4G2 \\ Correspondence should be addressed to A Akoum; Email: ali.akoum@crsfa.ulaval.ca
}

\begin{abstract}
Our previous studies showed a marked deficiency in interleukin 1 receptor type II (IL1R2) in the endometrial tissue of women with endometriosis, particularly in epithelial cells. We believe that such a deficiency in IL1R2, a potent and specific IL1 inhibitor, makes endometrial cells more sensitive to IL1 and less capable of buffering the cytokine's effects, which may lead to functional changes that favor endometriosis development. The main objective of our study was to stably inhibit IL1R2 expression in endometrial cells in order to evaluate the role of IL1R2 deficiency in endometriosis pathophysiology. Stable clones of Ishikawa adenocarcinoma endometrial cells transfected with IL1 R2 antisense and showing downregulation of IL1 R2 protein expression, or with the empty expression vector alone and showing no noticeable difference in IL1R2 expression, were selected. The downregulation of IL1R2 expression in IL1R2 antisense transfectants when compared with control cells was confirmed by ELISA, Western blot and immunofluorescence. In these cells, IL1R2 expression was markedly reduced, compared with non-transfected cells or cells transfected with the empty vector, and there was a significant increase in the basal and the IL1- $\beta$ (IL1B)-induced levels of matrix metalloproteinase (MMP)-2 and MMP-9 secretion. Furthermore, a significant decrease in IL1B-induced secretion of tissue inhibitor of MMPs-1, a known MMP-9 inhibitor, was observed. These in vitro data make plausible a role for IL1R2 deficiency in the capability of endometrial cells to invade the host tissue and develop in ectopic locations.
\end{abstract}

Reproduction (2007) 134 525-534

\section{Introduction}

Pro-inflammatory cytokines, particularly interleukin 1 (IL1), are involved in the modulation of a variety of endometrial functions (Tabibzadeh 1991, Simon et al. 1998). A tight control of IL1 effects is therefore necessary to maintain homeostasis and normal endometrial functions. IL1 receptor type I (IL1R1), the functional signaling receptor which mediates cell activation by IL1, is expressed in the human endometrium (Simon et al. 1993) and follows a gradually increasing expression pattern throughout the menstrual cycle (Bigonnesse et al. 2001). IL1R2, which has no signaling properties and rather acts as decoy receptor for IL1, is also expressed in the human endometrium and follows a more complex cycle-phase dependent expression pattern during the menstrual cycle (Boucher et al. 2001, Kharfi et al. 2002). Several studies suggest that IL1R2 plays an important physiological role in the regulation of IL1 action in the inflammatory sites by capturing IL1 and preventing its interaction with IL1R1 (Colotta et al. 1993, 1994, Bossu et al. 1995, Orlando et al. 1997, Coulter et al. 1999). Our previous data showed a marked deficiency in IL1R2 expression in the eutopic endometrial tissue of women with endometriosis, occurring at the protein (Akoum et al. 2001a) and the mRNA (Kharfi et al. 2002) levels, particularly in epithelial cells. Therefore, imbalance between the activating IL1R1 and the inhibitory IL1R2 in endometrial cells of women with endometriosis may result in increased cell reactivity to IL1 in the eutopic endometrial tissue, but likely in the ectopic locations as well and in response to local stimuli such as IL1, which may favor endometriosis development. This is all the more possible since either eutopic or ectopic endometrial cells of women with endometriosis showed increased sensitivity to IL1B (Akoum et al. 1995a, 1995b, 2001b, Sillem et al. 1999, 2001, 
Lebovic et al. 2000). Furthermore, elevated concentrations of IL1B were found in the peritoneal fluid (Mori et al. 1992, Taketani et al. 1992) and the ectopic endometrial tissue of women with endometriosis (Bergqvist et al. 2001). This emphasizes the role of this cytokine in the pathophysiology of the disease and further supports the relevance of our findings.

Therefore, the objective of the present study was to specifically inhibit IL1R2 expression in endometrial cells, and create a stably transfected endometrial cell line that will allow the assessment of the role of IL1R2 deficiency in IL1-mediated functional changes that may favor ectopic endometrial cell growth and endometriosis development. As IL1R2 deficiency was more obvious in endometrial epithelial cells (Boucher et al. 2001), a welldifferentiated endometrial epithelial adenocarcinoma cell line (Ishikawa cells; Nishida et al. 1985) which responds to IL1B (Makrigiannakis et al. 1999) was used as model and had undergone a stable transfection to block IL1R2 expression and to recreate the imbalance that we found in endometrial cells of patients with endometriosis.

\section{Material and Methods \\ Cell transfection}

For these studies, we used a well-differentiated endometrial adenocarcinoma cell line (Ishikawa cells; Nishida et al. 1985) which was stably transfected with the pcDNA expression vector alone or containing IL1R2 cDNA in the antisense direction. This line maintains functional estrogen and progesterone receptors and numerous endometrial epithelial cell functions (Croxtall et al. 1990, Hata \& Kuramoto 1992, Lessey et al. 1996, Castelbaum et al. 1997). Cell transfection was performed using Lipofectamine Plus reagent according to manufacturer's instructions (Invitrogen). Cells were seeded in 24-well culture plates (Costar, Cambridge, MA, USA), cultured in Dulbecco's modified Eagle medium-F12 medium (DMEM-F12) containing 10\% fetal bovine serum (FBS) and 1\% antibiotics (Invitrogen) until 70\% confluence, and incubated with DNA/lipofectamine complexes in FBS-free DMEM. After $3 \mathrm{~h}$ of incubation at $37{ }^{\circ} \mathrm{C}$, medium containing $10 \%$ FBS was added and culture continued for $24 \mathrm{~h}$. Cells were then passed $(1 / 20$ dilution) in a fresh culture medium containing $150 \mu \mathrm{g} / \mathrm{ml}$ geneticin (Sigma-Aldrich). After 1-2 weeks, individual growing colonies were selected and separately expanded in culture, in the presence of $150 \mu \mathrm{g} / \mathrm{ml}$ geneticin. A total of 32 clones were isolated from cultures transfected with the plasmid vector harboring or not IL1R2 CDNA in the antisense direction. Clones were assessed as described below and all experiments were repeated at least thrice.

\section{Culture stimulation}

Cells were cultured at $37^{\circ} \mathrm{C}$ in humidified $5 \% \mathrm{CO}_{2}$. Cultures grown to confluence were trypsinized, harvested by centrifugation, and distributed in 12-well culture plates (Costar) in DMEM-F12 containing $150 \mu \mathrm{g} / \mathrm{ml}$ geneticin (only for cells transfected with pcDNA plasmid) with $10 \%$ FBS. Medium was changed every 2 days until confluence. Before cell stimulation, the culture medium was replaced by a serum-free medium for $24 \mathrm{~h}$. Cells (three wells/treatment) were exposed or not to IL1B (0-10 ng/ml; Invitrogen) diluted in a fresh FBS-free medium for $24 \mathrm{~h}$. The culture supernatant was collected and kept in small aliquots at $-80{ }^{\circ} \mathrm{C}$ until used for ELISA and Western blotting. Cells were recovered in a lysis buffer solution containing $0.5 \%$ Triton X-100, $10 \mathrm{mM}$ HEPES (pH 7.4), $150 \mathrm{mM} \mathrm{NaCl}$, $2 \mathrm{mM}$ EGTA, $2 \mathrm{mM}$ EDTA and $0.02 \% \mathrm{NaN}_{3}$, and a mixture of anti-proteases composed of $5 \mu \mathrm{M}$ aprotinin, $63 \mu \mathrm{M}$ leupeptin, and $3 \mathrm{mM}$ phenylmethylsulfonylfluoride and kept at $-80{ }^{\circ} \mathrm{C}$.

\section{Protein extraction}

Cells recovered in the lysis buffer were disrupted by multiple passages through a tuberculin syringe with a 25 -gauge needle and incubated at $4{ }^{\circ} \mathrm{C}$ for 45 min under gentle shaking. After centrifugation at $11000 \mathrm{~g}$ for $30 \mathrm{~min}$, soluble protein extracts were collected and total protein concentration was determined using the Bio-Rad DC Protein Assay (Bio-Rad Laboratories Ltd).

\section{Western blotting}

The similar procedure was applied for Western blot analysis of IL1R1, IL1R2, and IL1R accessory protein (IL1RAcP). Ten micrograms of protein for IL1R1 and $20 \mu \mathrm{g}$ for IL1R2 and IL1RAcP were heated in a boiling bath for $5 \mathrm{~min}$ in $5 \times$ SDS sample buffer (1.25 M Tris- $\mathrm{HCl}(\mathrm{pH} 6.8)$, $50 \%$ glycerol, $25 \%$-mercaptoethanol, $10 \%$ SDS, and $0.01 \%$ bromophenol blue), separated by SDS-PAGE in $10 \%$ acrylamide linear gradient slab gels (IL1R1 and IL1R2) or in gradient slab gels ranging from 5 to $18 \%$ acrylamide (IL1RACP), and transferred onto $0.2 \mu \mathrm{m}$ nitrocellulose membranes (BioTraceNT; Pall Corporation, Ville St-Laurent, Québec, Canada) using electrophoretic transfer cell (Bio-Rad Laboratories Ltd). Recombinant soluble human (RSH) IL1R1, IL1R2, and IL1RAcP (R\&D Systems Inc., Minneapolis, MN, USA) were used as positive controls.

Equal loading in each lane was confirmed by staining the blots with Ponseau S. (2\%). Nitrocellulose membranes were then immersed in PBS containing 3\% skimmed milk and $0.1 \%$ Tween 20 (blocking solution) for $1 \mathrm{~h}$ at room temperature and cut into strips. Membranes were incubated for $3 \mathrm{~h}$ at room temperature with a polyclonal goat anti-human IL1R1 (R\&D Systems; 
$2 \mu \mathrm{g} / \mathrm{ml}$ in blocking solution), a polyclonal goat anti-human IL1R2 (R\&D Systems; $2 \mu \mathrm{g} / \mathrm{ml}$ in blocking solution), or a polyclonal goat anti-human IL1RAcP (R\&D Systems; $2 \mu \mathrm{g} / \mathrm{ml}$ in blocking solution). Equivalent concentrations of normal goat IgGs were used as controls. After six washes (5 min each in PBS/0.1\% Tween 20), the strips were incubated for $1 \mathrm{~h}$ at room temperature with Fc-specific peroxidase-labeled rabbit anti-goat antibody (1:10000 dilution in blocking solution; Jackson ImmunoResearch Laboratories Inc., West Grove, PA, USA). Membranes were finally washed and incubated for 1 min with an ECL Western blotting detection reagent (GE Healthcare Bio-Sciences Inc., Baie d'Urfé, Québec, Canada) and exposed to Fujifilm for 2-15 min for optimal detection (all bands visible but not overexposed). The $\alpha$-tubulin was used as a second control to ensure equal protein loading in each lane. Membranes were incubated for $1 \mathrm{~h}$ at room temperature with mouse anti- $\alpha$-tubulin antibody (Sigma-Aldrich; 1:50 000 dilution in washing solution). After three washes (5 min each), the strips were incubated for $45 \mathrm{~min}$ at room temperature in Fc-specific peroxidase-labeled goat antimouse antibody (1:10 000 dilution in washing solution; Jackson ImmunoResearch Laboratories), washed six times (5 min each), incubated for 1 min with an ECL Western blotting detection reagent (GE Healthcare BioSciences Inc.), and exposed to Fujifilm for 2-15 s for optimal detection (all bands visible but not overexposed).

\section{Immunofluorescence}

The same immunofluorescence procedure was applied for IL1R1, IL1R2, and IL1RAcP. Cells were seeded on eight-well sterile culture slides $\left(5 \times 10^{3}\right.$ cells/well; BD Biosciences, Mississauga, Ontario, Canada), cultured overnight without stimulation, washed once with PBS, and fixed for $15 \mathrm{~min}$ at room temperature with $\mathrm{PBS} / 3.7 \%$ formaldehyde. After washing with PBS, cells were incubated with PBS containing 1\% Triton X-100 for $15 \mathrm{~min}$ at room temperature, washed in PBS, and incubated with a monoclonal mouse anti-human IL1R1 (R\&D Systems; $10 \mu \mathrm{g} / \mathrm{ml}$ in PBS containing $0.2 \%$ bovine serum albumin (BSA) and $0.01 \%$ Tween 20 ), a monoclonal mouse anti-human IL1R2 (R\&D Systems; $10 \mu \mathrm{g} / \mathrm{ml}$ in PBS/BSA/Tween 20), or a polyclonal goat anti-human IL1RAcP (R\&D Systems; $10 \mu \mathrm{g} / \mathrm{ml}$ in PBS/BSA/Tween 20) for $1 \mathrm{~h}$ at room temperature in a humid chamber. For controls, cells were incubated with PBS/BSA/Tween 20 only. After washing with PBS containing 0.1\% Tween 20 and subsequently with PBS alone, cover slips were incubated for $1 \mathrm{~h}$ at room temperature with a biotinconjugated horse anti-mouse antibody (Vector Laboratories, Burlingame, CA, USA; 1:100 dilution in PBS/BSA/Tween 20) for IL1R1 and IL1R2 or with a biotinconjugated rabbit anti-goat $(\mathrm{H}+\mathrm{L}$; Jackson Immuno Research Laboratories; 1:100 dilution in PBS/BSA/Tween
20) for IL1RAcP. Subsequently, culture slides were washed with PBS and incubated with $1 \%$ streptavidin-fluorescein isothiocyanate in PBS/BSA/Tween 20 for $1 \mathrm{~h}$ at room temperature in a humid chamber. After a final wash in PBS, samples were mounted in Mowiol containing 10\% paraphenylenediamine (Sigma-Aldrich), an anti-fading agent, and observed under a Leica microscope (Leica Mikroskopie und Systeme, Wetzlar, Germany) equipped for fluorescence with a $100 \mathrm{~W}$ u.v. lamp and connected to an image analysis system (ISIS; Metasystems, Altlussheim, Germany).

\section{ELISA}

IL1R2, matrix metalloproteinase-2 (MMP-2), MMP-9, and tissue inhibitor of MMPs (TIMP)- 1 concentrations in Ishikawa cell culture supernatants were measured using an ELISA procedure previously developed in our laboratory (Kats et al. 2002, Collette et al. 2004, Bellehumeur et al. 2005).

\section{Zymography}

Gelatinase activity in samples of culture supernatants $(40 \mu \mathrm{l})$ was analyzed by zymography on $7.5 \%$ SDSpolyacrylamide gels containing $0.5 \mathrm{mg} / \mathrm{ml}$ gelatin under non-reducing conditions as described previously (Collette et al. 2004, Bellehumeur et al. 2005). An equal volume of culture supernatant from human fibrosarcoma HT1080 cell line known for releasing elevated proteolytic activity was used as control in each gel (a gift from Dr Éric Petitclerc, Québec City, PQ, Canada). Quantification of detectable gelatinases was achieved by computer assisted densitometry (Biolmage, Visage 110s, Genomic Solutions Inc., Ann Arbor, Michigan, USA). Data were expressed as percentage of control (HT1080 gelatinases). Assays were performed thrice in duplicates.

\section{Statistical analysis}

Data followed a parametric distribution and were shown as means \pm S.E.M. Comparison of two groups was performed using the unpaired $t$-test, whereas one-way ANOVA and the Bonferroni's test post hoc on selected pairs were used for multiple comparisons, i.e. controls (NT) versus each cell line for each dose of IL1B. Statistical analyses were performed using GraphPad Software, Prism 4.0 (GraphPad Software, San Diego, CA, USA). Differences were considered as statistically significant whenever a $P$ value $<0.05$ occurred.

\section{Results}

\section{Selection of cell clones}

In total, 15 clones with the empty plasmid vector (E clones) and 17 clones with the IL1R2 antisense 
plasmid (A clones) were generated. IL1R2 concentration in culture supernatants and cell lysates from each of these clones were measured by ELISA, so as to select $\mathrm{E}$ clones showing IL1R2 expression similar to that of NT Ishikawa cells and A clones having weak or absent IL1R2 expression. Two E clones (E03 and E11) and two A clones (A08 and A17) were selected. As shown in Fig. $1 A$ and B, IL1R2 concentrations in cell lysates and supernatants from E03 and E11 clones were equivalent to those of NT cells, whereas lower concentrations of IL1R2 in the cell lysates from A08 and A17 clones were noted $(P<0.01)$. Only A17 showed lower levels of IL1R2 in the culture supernatant $(P<0.05)$.

\section{Immunofluorescence analysis of IL1R1, IL1R2, and IL 1RACP expression}

IL1 receptors' expression in E and A clones was also compared with that of NT Ishikawa cells by immunofluorescence. Representative photomicrographs exhibited in Fig. 2 show IL1R1, IL1R2, and IL1RAcP expression. Only IL1R2 immunostaining was reduced in A08 and A17 clones compared with NT cells, whereas no noticeable change in IL1R1 and IL1RAcP immunostaining was noted.
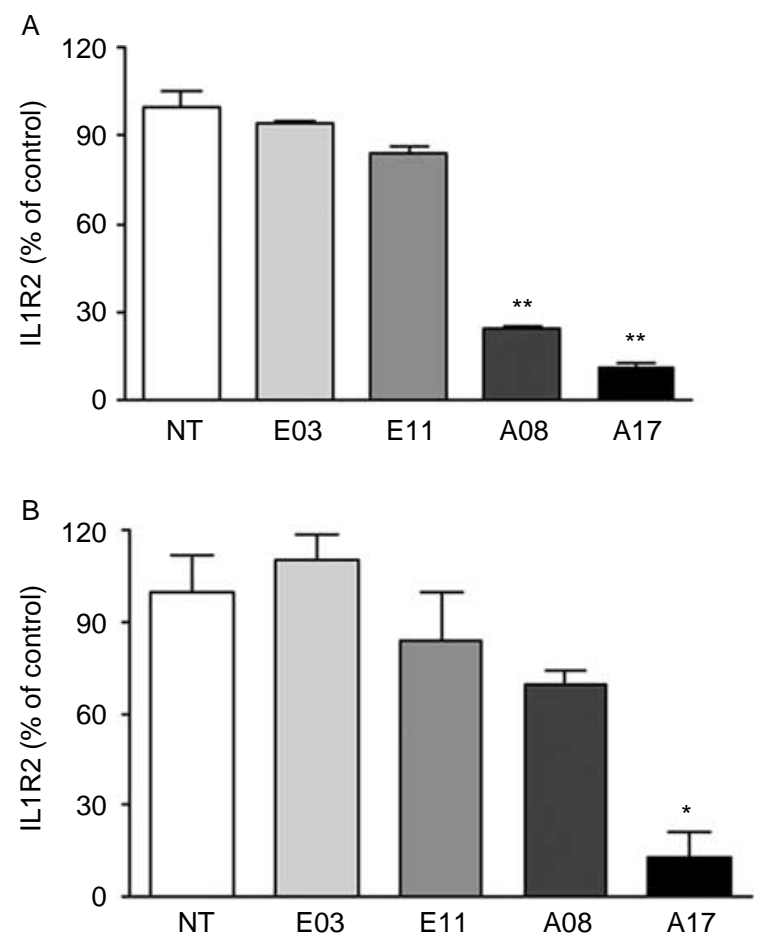

Figure 1 IL1R2 concentration as measured in cell lysates (A) and cellfree culture supernatants (B) by ELISA. Data from three independent experiments are shown as means \pm s.E.M. and presented as percentage of control (IL1R2 concentration in the culture supernatant of non-transfected (NT) cells). ${ }^{* *}$ Significant diminution of IL1R2 expression in A08 and A17 when compared with NT cells in cell lysates $(P<0.01)$. *Significant diminution of IL1R2 release in A17 when compared with NT cells in cell-free culture supernatants $(P<0.05)$.

\section{Western blot analysis of IL1R1, IL1R2, and IL1RACP expression}

To further evaluate IL1R1, IL1R2, and IL1RAcP expression, equivalent amounts of total cell protein extracts were analyzed by Western blotting. Western blot analysis of IL1R1 showed a $90 \mathrm{kDa}$ band whose apparent molecular weight (MW) corresponds to the membrane-bound form of IL1R1 (mblL1R1) as we previously reported (Bigonnesse et al. 2001), a generally faint $55 \mathrm{kDa}$ band corresponding to the soluble form of the receptor (sIL1R1) and three other bands of 79, 73, and $69 \mathrm{kDa}$, which may correspond to degraded IL1R1 protein (Fig. 3A). Western blot analysis of IL1R2 showed a major band of $68 \mathrm{kDa}$, which sometimes appeared as doublet of $68 / 70 \mathrm{kDa}$, corresponding to the reported MW of mbIL1R2, and a doublet of $44 / 45 \mathrm{kDa}$, which may correspond to two forms of sIL1R2 as we reported previously (Akoum et al. 2001a; Fig. 3B). Western blot analysis of IL1RAcP (Fig. 3C) showed one band at $\sim 61 \mathrm{kDa}$ which corresponds to mbIL1RAcP. Pre-absorption of IL1R1, IL1R2, and IL1RAcP antibodies with an excess of rshIL1R1, rshIL1R2, and rshIL1RAcP respectively before incubation with blotted proteins markedly reduced the intensity of the detected above-described bands, thereby demonstrating specific binding (data not shown). For the same amount of total proteins, the intensity of both mbIL1R2 and sIL1R2 was clearly lower in the A clones when compared with NT cells, whereas no noticeable change in the levels of IL1R1 and IL1RAcP expression was noted.

\section{Effect of IL1B on MMP-2 and MMP-9 secretion}

MMPs play a major role in endometriosis pathophysiology (Osteen et al. 2003, 2004), and according to our data there is an increased production and secretion of MMP-9 in the eutopic endometrial tissue of women with endometriosis, and, interestingly, a relationship with decreased sIL1R2 levels (Collette etal. 2004, 2006, Bellehumeur etal. 2005). The secretion of MMP-2 (Fig. 4A) and MMP-9 (Fig. 4B) in E and $A$ clones stimulated with varying concentrations of IL1B was therefore analyzed. Data shown in Fig. 4A showed that the basal level of MMP-2 secretion was significantly higher in A17 when compared with NT cells $(P<0.01)$. Furthermore, a significant increase in MMP-2 in response to $1 \mathrm{ng} / \mathrm{ml}$ IL1B was observed in the A08 clone when compared with NT cells $(P<0.05)$, whereas in the A17 clone a significant increase in MMP-2 secretion was observed at 0.1 and $1 \mathrm{ng} / \mathrm{ml}$ IL1B $(P<0.05)$. MMP-9 secretion in the A08 clone was significantly increased at 0.1 and $10 \mathrm{ng} / \mathrm{ml}(P<0.05)$. However, in the A017, a statistically significant increase was observed at $10 \mathrm{ng} / \mathrm{ml}$ IL1B $(P<0.05)$. No significant difference between E03 or E11 clone and NT cells was noted. 


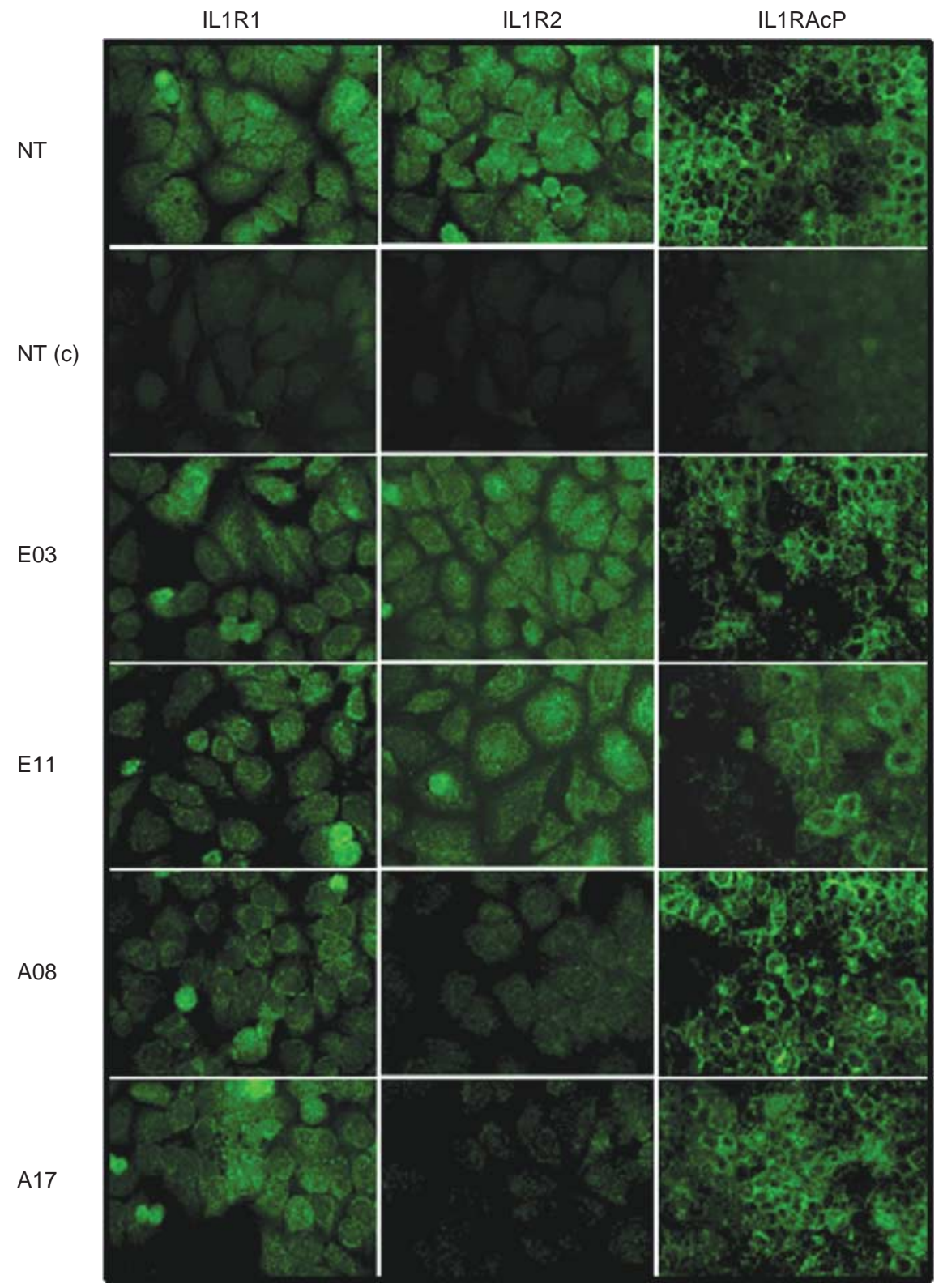

Figure 2 Immunofluorescence analysis of IL1R1, IL1R2, and IL1RAcP expression in non-transfected Ishikawa cells (NT) and E03, E11, A08, and A17 clones. Note the comparable intensity of IL1R1 and IL1RAcP immunofluorescent signals in NT, E03, and E11 clones, and the marked decline in IL1R2 immunofluorescent signal in A08 and A17 clones. No immunofluorescence was observed in negative controls (c) in the absence of primary antibodies (objective $\times 40$ ).
Culture supernatants from NT Ishikawa cells and from $E$ and $A$ clones stimulated with varying concentrations of IL1B were then analyzed by gelatinolytic zymography. As shown in Fig. 5 (assays run under the same conditions), one distinct band of gelatinase activity at $72 \mathrm{kDa}$ and corresponding to the latent form of MMP-2 (pro-MMP-2) was detected in the culture supernatants of NT and E clones. In the culture supernatants of A clones, the pro-MMP-2 band together with two additional 170 and $92 \mathrm{kDa}$ bands were detected. The $170 \mathrm{kDa}$ faint band might correspond to the putative dimeric MMP-9 pro-form (put-MMP-9) described by Watari et al. (1999) and identified by Western blotting in our previous studies (Collette et al. 2006), whereas the $92 \mathrm{kDa}$ band is consistent with the latent form of MMP-9. Densito- metric analysis of MMPs' lysis bands showed that proMMP-2 band was significantly more intense in the A08 and $\mathrm{A} 17$ clones than in NT Ishikawa cells incubated with the culture medium alone $(P<0.05$ and $P<0.01$ respectively) or supplemented with $0.1(P<0.01)$ and $1(P<0.01) \mathrm{ng} / \mathrm{ml}$ IL1B. At $10 \mathrm{ng} / \mathrm{ml}$ IL1B, only A08 showed a statistically significant increase in pro-MMP-2 gelatinolytic activity when compared with NT cells $(P<0.05)$. No statistically significant change in pro-MMP-2 activity was found in E03 and E11 clones when compared with NT cells was found, either with or without IL1B treatment (Fig. 6A). The gelatinolytic activity corresponding to pro-MMP-9 was detected only in the culture supernatants of A08 and A17 cells (Fig. 6B). However, no statistical analysis in comparison 

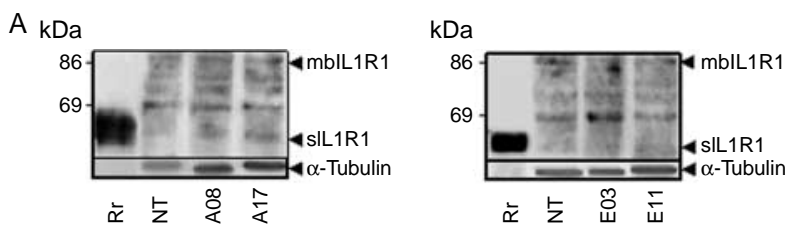

$\mathrm{B} \mathrm{kDa}$

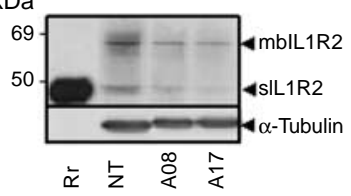

C $\mathrm{kDa}$

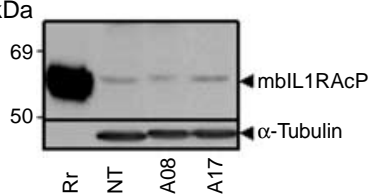

$\mathrm{kDa}$
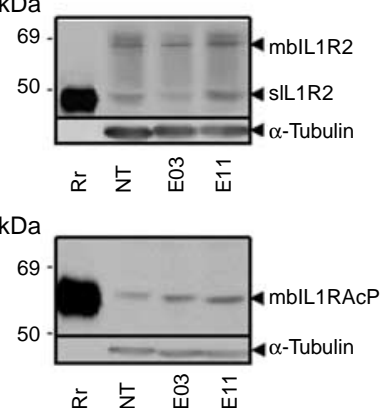

Figure 3 Representative Western blot analysis of IL1R1 (A), IL1R2 (B), and IL1RACP (C) expression in non-transfected Ishikawa cells (NT) and E03, E11, A08, and A17 clones. Equal amounts of proteins were subjected to SDS-PAGE analysis and Western blotting. Recombinant IL1R1, IL1R2, and IL1RAcP proteins were taken as controls (rR). Blotting with anti-tubulin antibody demonstrates equal protein loading. Note the reduced intensity of IL1R2 bands corresponding to either the membrane-bound or the soluble forms of the receptor, when compared with NT cells, and the absence of noticeable change in IL1R1 and IL1RAcP expression; mb, membrane-bound; s, soluble.

with NT cells was carried out, as no gelatinolytic activity corresponding to pro-MMP-9 was detected in the culture supernatant of NT cells. These data further demonstrate higher secretion of MMP-2 and MMP-9 in the A clones when compared with NT cells. It is noteworthy that the 66 and the $86 \mathrm{kDa}$ bands, which correspond to active MMP-2 and MMP-9 forms respectively, were detected in the culture supernatant of HT-1080 cells (control), but rarely in the culture supernatants of NT Ishikawa cells or the $\mathrm{E}$ and $\mathrm{A}$ clones.

\section{Effect of IL1B on TIMP-1 secretion}

Measurement of TIMP-1 concentrations in the culture supernatants by ELISA and statistical analysis of the data showed a diminution of TIMP-1 secretion in the A17 clone when compared with NT cells in response to IL1B, with statistically significant differences observed at 0.1 and $1 \mathrm{ng} / \mathrm{ml}$ IL1B $(P<0.05)$. No statistically significant change in TIMP-1 secretion in NT cells or the E03, E11, and A08 clones was seen (Fig. 7).

\section{Discussion}

To study the effects of IL1R2 deficiency in endometrial cells on the functional modifications which can promote their ectopic development, the Ishikawa adenocarcinoma endometrial cell line was stably transfected with the pcDNA expression vector alone or containing IL1R2 CDNA in the antisense direction. The purpose of this
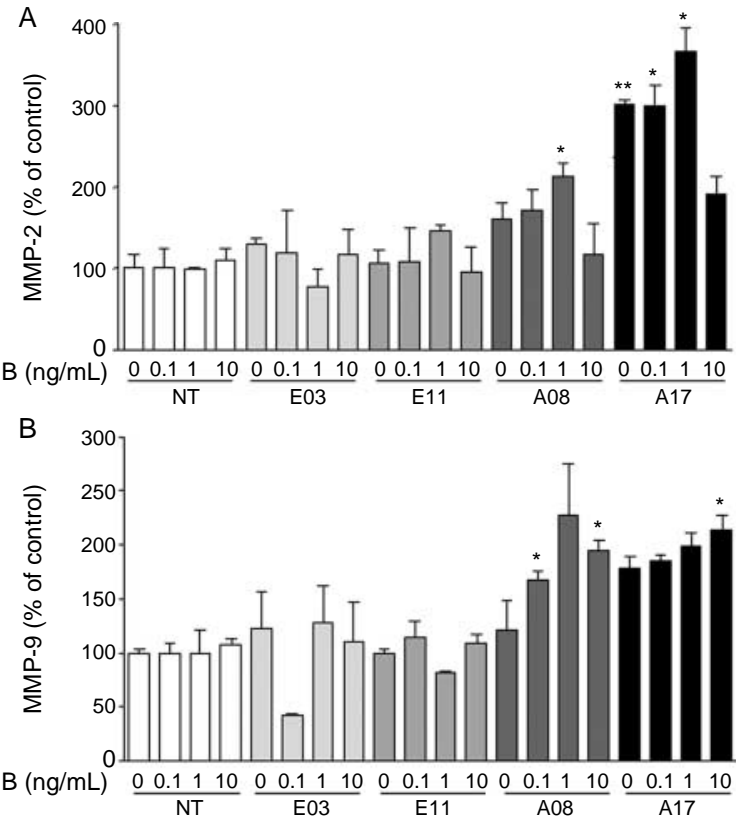

Figure 4 Measurement of MMP-2 (A) and MMP-9 (B) secretion in nontransfected Ishikawa cells (NT) and E03, E11, A08, and A17 clones. Cells were stimulated for $24 \mathrm{~h}$ with different concentrations of IL1B (0-10 ng/ml). MMP-2 and MMP-9 concentrations were measured in cell-free supernatants by ELISA. Data from three independent experiments are shown as means \pm s.E.M. and presented as percentage of control (MMP-2 or MMP-9 concentration in the culture supernatant of NT cells incubated in the culture medium alone without IL1B). * and **, statistically significant increase of MMPs, when compared with NT cells stimulated or not with an equivalent concentration of IL1B $(P<0.05$ and $P<0.01$ respectively).

transfection was to recreate the deficiency in IL1R2 that we found in endometrial cells of women with endometriosis and the resulting imbalance in cell responsiveness to IL1. In fact, a decreased expression of IL1R2, a specific downregulator of IL1 action, was shown in endometrial cells, either at the protein or the mRNA level (Boucher et al. 2001, Kharfi et al. 2002). These data are supported by other findings showing an increased sensitivity to IL1B in eutopic and ectopically implanted endometrial cells (Akoum et al. $1995 a, 1995 b, 2001 b, 2002)$. This is in line with other studies showing that IL1A/IL1B exerts more pronounced effects on endometrial cell adhesion (Sillem et al. 1999), and that MMP-3 (stromelysin-1) expression is increased after exposure to IL1A/IL1B and may promote invasion and remodeling of the host tissue (Sillem et al. 2001). Lebovic et al. (2000) showed enhanced production of angiogenic molecules such as vascular endothelial cell growth factor and IL6 in response to IL1B in endometriotic cells when compared with endometrial cells from normal women. Therefore, IL1, a major pro-inflammatory and multifunctional cytokine, may play a central role in the inflammatory cascade associated with endometriosis and in propagating endometriotic implants through a proinflammatory stimulus and the synthesis of chemokines, growth, remodeling, and angiogenic factors (Akoum et al. 

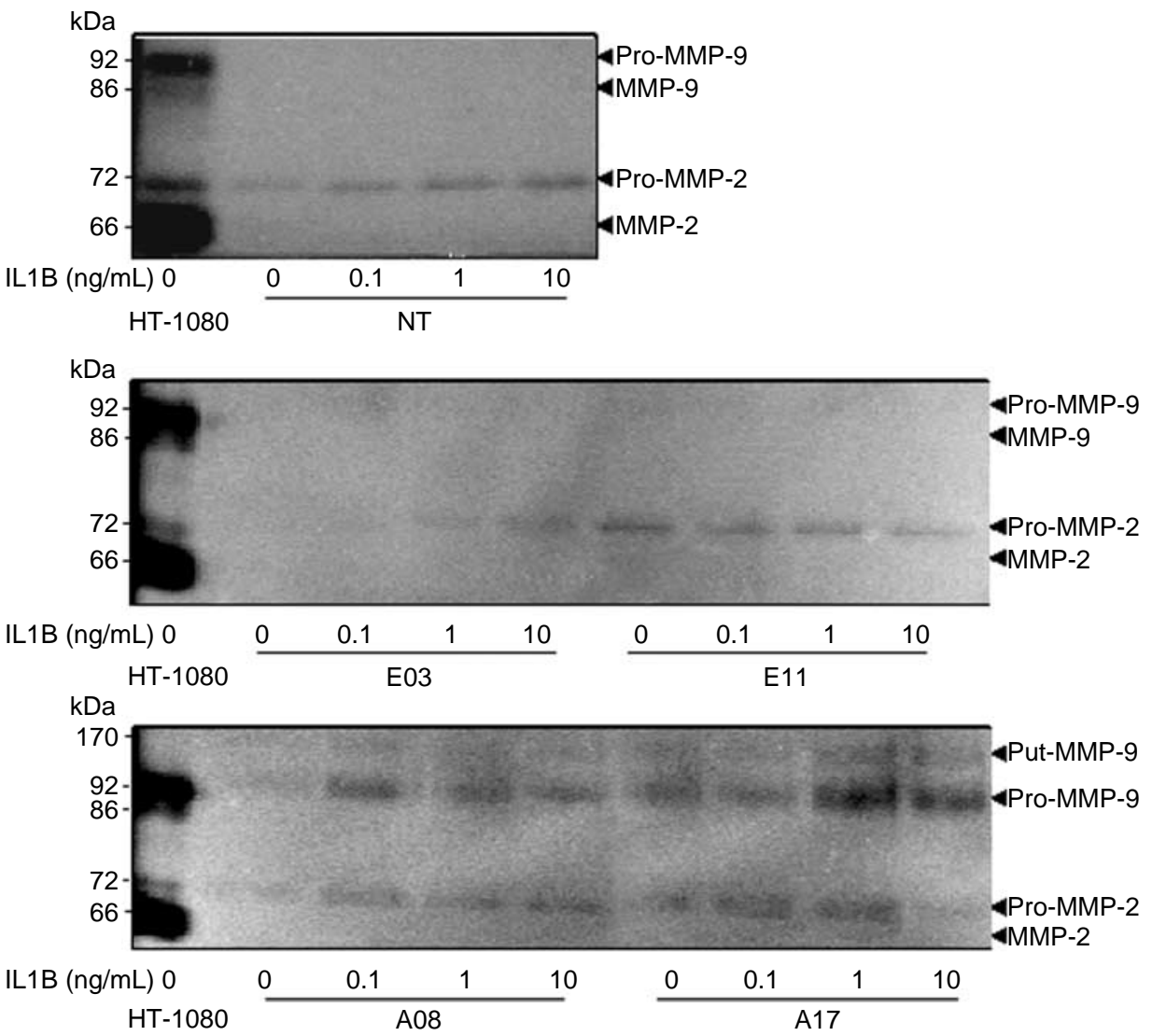

Figure 5 Assessment of gelatinase activity by zymography. Non-transfected (NT), E03, E11, A08, and A17 cells were stimulated for $24 \mathrm{~h}$ with different concentrations of IL1B $(0-10 \mathrm{ng} / \mathrm{ml})$. Samples of cell-free culture supernatants were analyzed by zymography in gels impregnated with gelatin under non-reducing conditions. Representative zymograms showing lysis bands corresponding to the latent and active forms of MMP-2 and MMP-9. Only pro-MMP-2 band was detected in the culture supernatants of NT and E cells, whereas in addition to pro-MMP-2, two bands corresponding to putative (put)-MMP-9 and pro-MMP-9 were detected in the culture supernatants of A cells. Active MMP-2 and MMP-9 forms, which were obvious in the culture supernatant of HT-1080 cell line, were not observed in the culture supernatants of NT, E, or A cells. 1995a, 1996, 2001b, Lebovic et al. 2000, 2001, Sillem et al. 2001). In women with endometriosis, peritoneal macrophages, whose number and activation level were shown to increase in the peritoneal cavity of patients (Mori et al. 1992), secrete elevated levels of IL1B. Elevated concentrations of IL1B were found in the peritoneal fluid of women suffering from endometriosis (Mori et al. 1992, Taketani et al. 1992). Interestingly, recent studies showed an increased expression of IL1B in the ectopic endometrium of women with endometriosis (Bergqvist et al. 2001) which highlights the role of this cytokine in the pathophysiology of the disease.

All generated clones were first analyzed by ELISA in cell lysates and we report here a marked diminution in IL1R2 concentrations in two cell clones stably transfected with IL1R2 antisense when compared with NT cells or to cells transfected with the empty expression vector. It is noteworthy that transfection of the A clones was not always successful, and varied largely between the selected clones. Considering that the receptor can be cleaved and shed from the cell surface by the proteolytic action of matrix metalloproteases (Orlando et al. 1997), where sIL1R2 can prevent the interaction of IL1B with the signal-transducing IL1R1 (Colotta et al. 1993), IL1R2 ELISA in the cell-free supernatants was necessary and demonstrated a reduced release of IL1R2. Further analysis of IL1 receptors by immunofluorescence and
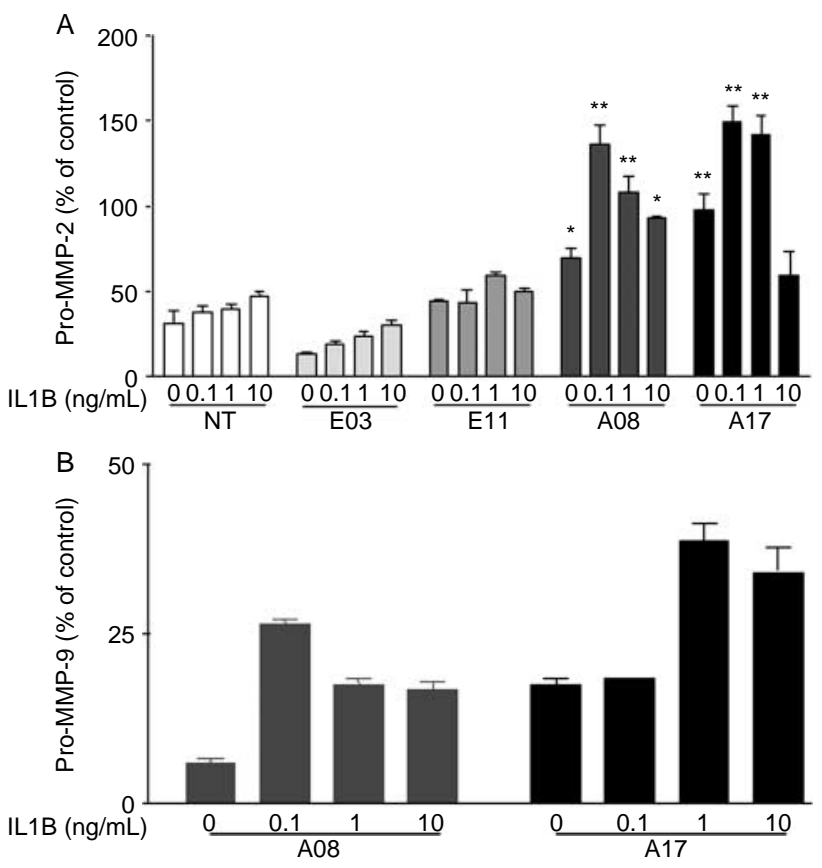

Figure 6 Densitometric analysis of MMP-2 (A) and MMP-9 (B) lysis bands following zymography. Data are means \pm s.E.M. and expressed as percentage of control (corresponding HT1080 MMP-9 and MMP-2 bands). ${ }^{*}, * *$ Significant difference with NT cells for similar IL1B concentration $(P<0.05$ and $P<0.01$ respectively). 


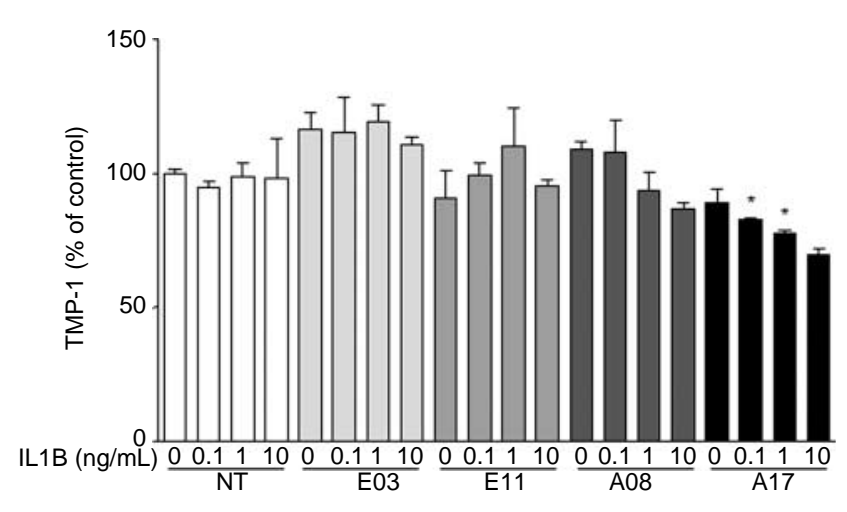

Figure 7 Measurement of TIMP-1 secretion in non-transfected Ishikawa cells (NT) and E03, E11, A08, and A17 clones. Cells were stimulated for $24 \mathrm{~h}$ with different concentrations of IL1B $(0-10 \mathrm{ng} / \mathrm{ml})$. TIMP-1 concentration was measured in cell-free supernatants by ELISA. Data from three independent experiments were shown as means \pm S.E.M. and presented as percentage of control. *Statistically significant increase of TIMP-1, when compared with NT cells stimulated or not with an equivalent concentration of IL1B $(P<0.05)$.

Western blot clearly showed that the selected A clones had a reduced expression of IL1R2, which is in keeping with the ELISA data, whereas IL1R1 and IL1RAcP expression remained unchanged.

In women with endometriosis, several studies showed an increased expression in ectopic and eutopic endometrial tissues of several proteases including MMPs (Bergqvist et al. 1996, Chung et al. 2001, 2002, Bruse et al. 2004, Collette et al. 2004, 2006). These enzymes have been involved in the invasive establishment of the disease (Gilabert-Estelles et al. 2003, Osteen et al. 2003). In addition, MMPs expression appeared to be involved in the implantation of endometrial tissues since the establishment of ectopic endometriotic lesions failed when MMPs secretion was blocked (Bruner et al. 1997). In the same way, it has been reported that MMP-2 (Wenzl \& Heinzl 1998) and MMP-9 expression was increased in endometriotic lesions (Chung et al. 2001). In the present study, we found that MMP-2 and MMP-9 secretion was increased in the $A$ clones in response to IL1B. Furthermore, there was a significant dose-dependent decrease in TIMP-1 secretion in response to IL1B in the A17 clone, which interestingly had the most significantly reduced IL1R2 levels. This suggests that reducing IL1R2 levels and consequently increasing cell responsiveness to IL1B may contribute to an imbalance in the expression of the MMPs 2 and 9 and that of TIMP-1.

Natural tissue inhibitors of MMPs and TIMPs are especially important in regulating extracellular matrix remodeling since they regulate MMP activity. An imbalance between MMP and TIMP expression has been involved in various medical conditions, notably rheumatoid arthritis, tumor invasion, and endometriosis (see Osteen et al. 2003 for review). TIMP-1 is involved in the regulation of the active forms of MMP-1, MMP-3, and MMP-9, and has the capacity to form a complex with pro-
MMP-9, thereby blocking the activation of the enzyme (Goldberg et al. 1992, Hanemaaijer et al. 1993). Interestingly, TIMP-1 concentration was found to be decreased in the peritoneal fluid of endometriosis patients when compared with normal controls (Sharpe-Timms et al. 1998). We reported a significant decrease in TIMP-1 secretion an imbalance between MMP-9 and TIMP-1 levels in the endometrial tissue of women with endometriosis when compared with normal women (Collette et al. 2004, 2006). We also showed a relationship between MMP-9 and IL1R2 expression in the eutopic endometrium of women with endometriosis, and a proteolytic post-translational mechanism by which MMP-9 directly contribute to downregulating IL1R2 levels (Bellehumeur et al. 2005). Taken together, these data suggest that IL1B-induced secretion of MMPs and downregulation of TIMP-1 may play a role in the exacerbation of endometrial cell responsiveness to IL1 and the local inflammatory reaction observed in endometriosis.

In conclusion, our study led to the generation of stably transfected Ishikawa adenocarcinoma endometrial cells with reduced expression of IL1R2 and no noticeable change in IL1R1 and IL1RACP expression. Furthermore, our results showed that abnormal IL1R2 expression was associated with a significant increase in MMP-2 and MMP-9 secretion and a concomitant decrease in TIMP-1 secretion in response to IL1B. In view of the pluripotent effects of IL1 and its well-documented role in endometriosis pathophysiology, the role of MMPs in tissue remodeling and the marked upregulation of these factors in ectopic and eutopic endometrial tissues of endometriosis women, our in vitro data make plausible the role of IL1R2 deficiency in the acquisition by endometrial cells of endometriosis women of abnormal functions that may enable them to invade and implant into the host tissue. Delineation of the mechanisms underlying the capacity of endometrial cells to implant ectopically and respond differently to IL1 and identification of the resulting abnormal functions may be of interest for a better understanding of endometriosis pathophysiology and ultimately for the development of new diagnosis tools and targeted therapies.

\section{Acknowledgements}

This work is supported by grant MOP-14638 to Ali Akoum from The Canadian Institutes for Health Research. A Akoum is Chercheur National from the Fonds de la Recherche en Santé du Québec (FRSQ). The authors wish to thank Dr Yves Labelle, Unité de Génétique Humaine et Moléculaire, Centre de Recherche, Hôpital Saint-François d'Assise, CHUQ for precious help in cell transfection, and Vanessa Moisan, Annie Spahr, Marie-Josée Therriault and Rouslan Kats for technical assistance. The authors declare that there is no conflict of interest that would prejudice the impartiality of this scientific work. 


\section{References}

Akoum A, Lemay A, Brunet C \& Hebert J 1995a Cytokine-induced secretion of monocyte chemotactic protein-1 by human endometriotic cells in culture. The Groupe d'Investigation en Gynecologie. American Journal of Obstetrics and Gynécology 172 594-600.

Akoum A, Lemay A, Brunet C \& Hebert J 1995b Secretion of monocyte chemotactic protein-1 by cytokine-stimulated endometrial cells of women with endometriosis. Le groupe $d^{\prime}$ investigation en gynécologie. Fertility and Sterility 63 322-328.

Akoum A, Lemay A, Paradis I, Rheault N \& Maheux R 1996 Secretion of interleukin- 6 by human endometriotic cells and regulation by proinflammatory cytokines and sex steroids. Human Reproduction $112269-2275$.

Akoum A, Jolicoeur C, Kharfi A \& Aube M 2001a Decreased expression of the decoy interleukin-1 receptor type II in human endometriosis. American Journal of Pathology 158 481-489.

Akoum A, Lawson C, McColl S \& Villeneuve M 2001b Ectopic endometrial cells express high concentrations of interleukin (IL)-8 in vivo regardless of the menstrual cycle phase and respond to oestradiol by up-regulating IL-1-induced IL-8 expression in vitro. Molecular Human Reproduction 7 859-866.

Akoum A, Lemay A \& Maheux R 2002 Estradiol and interleukin-1 $\beta$ exert a synergistic stimulatory effect on the expression of the chemokine regulated upon activation, normal T cell expressed, and secreted in endometriotic cells. Journal of Clinical Endocrinology and Metabolism 87 5785-5792.

Bellehumeur C, Collette T, Maheux R, Mailloux J, Villeneuve M \& Akoum A 2005 Increased soluble interleukin-1 receptor type II proteolysis in the endometrium of women with endometriosis. Human Reproduction 20 1177-1184.

Bergqvist A, Ferno M \& Mattson S 1996 A comparison of cathepsin D levels in endometriotic tissue and in uterine endometrium. Fertility and Sterility 65 1130-1134.

Bergqvist A, Bruse C, Carlberg M \& Carlstrom K 2001 Interleukin $1 \beta$, interleukin-6, and tumor necrosis factor- $\alpha$ in endometriotic tissue and in endometrium. Fertility and Sterility 75 489-495.

Bigonnesse F, Labelle Y \& Akoum A 2001 Triphasic expression of interleukin-1 receptor type I in human endometrium throughout the menstrual cycle of fertile women and women with unexplained infertility. Fertility and Sterility 75 79-87.

Bossu P, Visconti U, Ruggiero P, Macchia G, Muda M, Bertini R, Bizzarri C, Colagrande A, Sabbatini V, Maurizi G et al. 1995 Transfected type II interleukin-1 receptor impairs responsiveness of human keratinocytes to interleukin-1. American Journal of Pathology 147 1852-1861.

Boucher A, Kharfi A, Al-Akoum M, Bossu P \& Akoum A 2001 Cycledependent expression of interleukin-1 receptor type II in the human endometrium. Biology of Reproduction 65 890-898.

Bruner KL, Matrisian LM, Rodgers WH, Gorstein F \& Osteen KG 1997 Suppression of matrix metalloproteinases inhibits establishment of ectopic lesions by human endometrium in nude mice. Journal of Clinical Investigation 99 2851-2857.

Bruse C, Radu D \& Bergqvist A 2004 In situ localization of mRNA for the fibrinolytic factors UPA, PAI-1 and UPAR in endometriotic and endometrial tissue. Molecular Human Reproduction 10 159-166.

Castelbaum AJ, Ying L, Somkuti SG, Sun J, Ilesanmi AO \& Lessey BA 1997 Characterization of integrin expression in a well differentiated endometrial adenocarcinoma cell line (Ishikawa). Journal of Clinical Endocrinology and Metabolism 82 136-142.

Chung HW, Wen Y, Chun SH, Nezhat C, Woo BH \& Lake Polan M 2001 Matrix metalloproteinase- 9 and tissue inhibitor of metalloproteinase-3 mRNA expression in ectopic and eutopic endometrium in women with endometriosis: a rationale for endometriotic invasiveness. Fertility and Sterility 75 152-159.

Chung HW, Lee JY, Moon HS, Hur SE, Park MH, Wen Y \& Polan ML 2002 Matrix metalloproteinase-2, membranous type 1 matrix metalloproteinase, and tissue inhibitor of metalloproteinase-2 expression in ectopic and eutopic endometrium. Fertility and Sterility 78 787-795.

Collette T, Bellehumeur C, Kats R, Maheux R, Mailloux J, Villeneuve M \& Akoum A 2004 Evidence for an increased release of proteolytic activity by the eutopic endometrial tissue in women with endometriosis and for involvement of matrix metalloproteinase-9. Human Reproduction 19 1257-1264.

Collette T, Maheux R, Mailloux J \& Akoum A 2006 Increased expression of matrix metalloproteinase-9 in the eutopic endometrial tissue of women with endometriosis. Human Reproduction 21 3059-3067.

Colotta F, Re F, Muzio M, Bertini R, Polentarutti N, Sironi M, Giri JG, Dower SK, Sims JE \& Mantovani A 1993 Interleukin-1 type II receptor: a decoy target for IL-1 that is regulated by IL-4. Science 261 472-475.

Colotta F, Dower SK, Sims JE \& Mantovani A 1994 The type II 'decoy' receptor: a novel regulatory pathway for interleukin 1 . Immunology Today 15 562-566.

Coulter KR, Wewers MD, Lowe MP \& Knoell DL 1999 Extracellular regulation of interleukin (IL)-1 $\beta$ through lung epithelial cells and defective IL-1 type II receptor expression. American Journal of Respiratory Cell and Molecular Biology 20 964-975.

Croxtall JD, Elder MG \& White JO 1990 Hormonal control of proliferation in the Ishikawa endometrial adenocarcinoma cell line. Journal of Steroid Biochemistry 35 665-669.

Gilabert-Estelles J, Estelles A, Gilabert J, Castello R, Espana F, Falco C, Romeu A, Chirivella M, Zorio E \& Aznar J 2003 Expression of several components of the plasminogen activator and matrix metalloproteinase systems in endometriosis. Human Reproduction 18 1516-1522.

Goldberg GI, Strongin A, Collier IE, Genrich LT \& Marmer BL 1992 Interaction of 92-kDa type IV collagenase with the tissue inhibitor of metalloproteinases prevents dimerization, complex formation with interstitial collagenase, and activation of the proenzyme with stromelysin. Journal of Biological Chemistry 267 4583-4591.

Hanemaaijer R, Koolwijk P, le Clercq L, de Vree WJ \& van Hinsbergh VW 1993 Regulation of matrix metalloproteinase expression in human vein and microvascular endothelial cells. Effects of tumour necrosis factor $\alpha$, interleukin 1 and phorbol ester. Biochemical Journal 296 803-809.

Hata H \& Kuramoto H 1992 Immunocytochemical determination of estrogen and progesterone receptors in human endometrial adenocarcinoma cells (Ishikawa cells). Journal of Steroid Biochemistry and Molecular Biology 42 201-210.

Kats R, Collette T, Metz CN \& Akoum A 2002 Marked elevation of macrophage migration inhibitory factor in the peritoneal fluid of women with endometriosis. Fertility and Sterility 78 69-76.

Kharfi A, Boucher A \& Akoum A 2002 Abnormal interleukin-1 receptor type II gene expression in the endometrium of women with endometriosis. Biology of Reproduction 66 401-406.

Lebovic DI, Bentzien F, Chao VA, Garrett EN, Meng YG \& Taylor RN 2000 Induction of an angiogenic phenotype in endometriotic stromal cell cultures by interleukin-1 $\beta$. Molecular Human Reproduction 6 269-275.

Lebovic DI, Chao VA, Martini JF \& Taylor RN 2001 IL-1 $\beta$ induction of RANTES (regulated upon activation, normal T cell expressed and secreted) chemokine gene expression in endometriotic stromal cells depends on a nuclear factor- $\mathrm{KB}$ site in the proximal promoter. Journal of Clinical Endocrinology and Metabolism 86 4759-4764.

Lessey BA, Ilesanmi AO, Castelbaum AJ, Yuan L, Somkuti SG, Chwalisz K \& Satyaswaroop PG 1996 Characterization of the functional progesterone receptor in an endometrial adenocarcinoma cell line (Ishikawa): progesterone-induced expression of the $\alpha 1$ integrin. Journal of Steroid Biochemistry and Molecular Biology $\mathbf{5 9}$ 31-39. 
Makrigiannakis A, Margioris AN, Zoumakis E, Stournaras C \& Gravanis A 1999 The transcription of corticotropin-releasing hormone in human endometrial cells is regulated by cytokines. Neuroendocrinology 70 451-459.

Mori H, Sawairi M, Nakagawa M, Itoh N, Wada K \& Tamaya T 1992 Expression of interleukin-1 (IL-1) $\beta$ messenger ribonucleic acid (mRNA) and IL-1 receptor antagonist mRNA in peritoneal macrophages from patients with endometriosis. Fertility and Sterility $\mathbf{5 7}$ 535-542.

Nishida M, Kasahara K, Kaneko M, Iwasaki H \& Hayashi K 1985 Establishment of a new human endometrial adenocarcinoma cell line, Ishikawa cells, containing estrogen and progesterone receptors. Nippon Sanka Fujinka Gakkai Zasshi 37 1103-1111.

Orlando S, Sironi M, Bianchi G, Drummond AH, Boraschi D, Yabes D \& Mantovani A 1997 Role of metalloproteases in the release of the IL-1 type II decoy receptor. Journal of Biological Chemistry 272 31764-31769.

Osteen KG, Yeaman GR \& Bruner-Tran KL 2003 Matrix metalloproteinases and endometriosis. Seminars in Reproductive Medicine $\mathbf{2 1}$ 155-164.

Osteen KG, Igarashi TM, Yeaman GR \& Bruner-Tran KL 2004 Steroid and cytokine regulation of matrix metalloproteinases and the pathophysiology of endometriosis. Gynecologic and Obstetric Investigation 57 53-54.

Sharpe-Timms KL, Keisler LW, McIntush EW \& Keisler DH 1998 Tissue inhibitor of metalloproteinase- 1 concentrations are attenuated in peritoneal fluid and sera of women with endometriosis and restored in sera by gonadotropin-releasing hormone agonist therapy. Fertility and Sterility 69 1128-1134.

Sillem M, Prifti S, Monga B, Arslic T \& Runnebaum B 1999 Integrinmediated adhesion of uterine endometrial cells from endometriosis patients to extracellular matrix proteins is enhanced by tumor necrosis factor alpha (TNF $\alpha$ ) and interleukin-1 (IL-1). European Journal of Obstetrics, Gynecology, and Reproductive Biology 87 123-127.
Sillem M, Prifti S, Koch A, Neher M, Jauckus J \& Runnebaum B 2001 Regulation of matrix metalloproteinases and their inhibitors in uterine endometrial cells of patients with and without endometriosis. European Journal of Obstetrics, Gynecology, and Reproductive Biology 95 167-174.

Simon C, Piquette GN, Frances A \& Polan ML 1993 Localization of interleukin-1 type I receptor and interleukin-1 $\beta$ in human endometrium throughout the menstrual cycle. Journal of Clinical Endocrinology and Metabolism 77 549-555.

Simon C, Moreno C, Remohi J \& Pellicer A 1998 Cytokines and embryo implantation. Journal of Reproductive Immunology 39 117-131.

Tabibzadeh S 1991 Human endometrium: an active site of cytokine production and action. Endocrine Reviews 12 272-290.

Taketani Y, Kuo TM \& Mizuno M 1992 Comparison of cytokine levels and embryo toxicity in peritoneal fluid in infertile women with untreated or treated endometriosis. American Journal of Obstetrics and Gynecology 167 265-270.

Watari M, Watari H, DiSanto ME, Chacko S, Shi GP \& Strauss JF III 1999 Pro-inflammatory cytokines induce expression of matrixmetabolizing enzymes in human cervical smooth muscle cells. American Journal of Pathology 154 1755-1762.

Wenzl RJ \& Heinzl H 1998 Localization of matrix metalloproteinase-2 in uterine endometrium and ectopic implants. Gynecologic and Obstetric Investigation 45 253-257.

Received 18 December 2006

First decision 23 January 2007

Revised manuscript received 23 May 2007

Accepted 29 May 2007 